\title{
A Parallel, Conjoined Approach to Interdisciplinary Computer Science Education
}

\author{
Thomas Way ${ }^{1}$ and Seth Whidden ${ }^{2}$ \\ Villanova University \\ Departments of ${ }^{1}$ Computing Sciences and ${ }^{2}$ Romance Languages \& Literatures \\ 800 Lancaster Avenue \\ Villanova, PA 19803, USA \\ $+1610-519-7307$ \\ thomas.way@villanova.edu
}

\begin{abstract}
This poster presents the results of two full cycles of a novel approach to Computer Science education that simplifies many of the pedagogical, organizational and administrative challenges in reaching across disciplines. We introduce a parallel, conjoined approach to constructing interdisciplinary offerings between Computer Science and a wide variety of other disciplines in a loosely-coupled fashion. Cooperating courses run simultaneously in nearby classrooms and meet together to collaborate numerous times during a semester. We describe our approach, lessons learned, results of evaluations of the effectiveness of the approach, and ideas for replicating the approach in other disciplines and institutions.
\end{abstract}

\section{CCS Concepts}

- Social and professional topics $\rightarrow$ Computing education $\rightarrow$ Computational thinking $\bullet$ Applied Computing $\rightarrow$ Education $\rightarrow$ Collaborative learning.

\section{Keywords}

Interdisciplinary courses; distributed expertise; machine translation; natural language processing; writing; stylistics.

\section{INTRODUCTION}

The breathtaking pace of change in computing and technology, and its widespread adoption in virtually every human endeavor, has led us to the dawn of a never before seen era of interdisciplinarity where some understanding of computing is necessary to be an active member of society [2]. Many barriers exist within the academic world including siloed specialization, disciplinary differences to teaching and learning, differing emphasis on interdisciplinarity, and a host of institutional, administrative and logistic issues. Traditional approaches to interdisciplinary education often involve a merging of subjects into a single course, with two or more faculty members collaborating on the content, design and offering. Faculty can find the effort fulfilling, but also labor intensive and cumbersome. Administrators find the idea compelling, but wrestle with designating course categories, justifying faculty expenditures and assigning teaching credit. [1]

Permission to make digital or hard copies of part or all of this work for personal or classroom use is granted without fee provided that copies are not made or distributed for profit or commercial advantage and that copies bear this notice and the full citation on the first page. Copyrights for thirdparty components of this work must be honored. For all other uses, contact the Owner/Author.

Copyright is held by the owner/author(s)

ITiCSE'16, July 09-13, 2016, Arequipa, Peru ACM 978-1-4503-4231-5/16/07.

http://dx.doi.org/10.1145/2899415.2925486

\section{APPROACH}

Our parallel, conjoined approach to interdisciplinary course design that uses a loosely-coupled structure [3] contrasts with the more common tightly-coupled approach as we rely on collaborating instructors offering simultaneous courses in nearby classrooms. After two successful iterations (and a third planned for Fall 2016) of collaboratively teaching previously independent offerings of Machine Translation (Computer Science) and Writing and Stylistics in French (French), we are confident this approach addresses many concerns regarding interdisciplinary computer science education pairings.

We first identified a desire to collaborate across disciplines and identified two courses that had cross-over potential. Prior to our offering, we identified seven to ten "join points" for our classes to meet and collaborate on learning and projects. The French course involved literature analysis and the Computer Science course devised tools and techniques for analyzing and transforming language, including ways that would benefit project goals of the French students. The courses met on the same days and times in adjacent classrooms. Departmental and college level buy-in was easy, as previous outcomes and objective for both courses remained in effect. Combined activities included accessible lecture materials from both disciplines, demonstrations of language analysis software by Computer Science students, descriptions of analysis goals by French students, and sessions where cross-discipline, team worked together to design, create and use software tools.

A measure of learning effectiveness and ample anecdotal evidence support the merits of our approach. Students and faculty report increased contextual and cross-disciplinary understanding. Benefits, lessons learned and future plans for implementation with other non-Computer Science disciplines are presented.

\section{ACKNOWLEDGMENTS}

This project was funded in part by NSF CPATH award IS-0829616 and a VITAL institutional course development grant.

\section{REFERENCES}

[1] Lori Carter. "Interdisciplinary computing classes: worth the effort." SIGCSE Technical Symposium (SIGCSE 2014), pp. 445-450, 2014.

[2] Lillian N. Cassel. "Interdisciplinary computing is the answer: now, what was the question?" ACM Inroads, vol. 2, no. 1, pp. 4-6, March 2011.

[3] Thomas Way and Seth Whidden. "A Loosely-Coupled Approach to Interdisciplinary Computer Science Education." Frontiers in Education: Computer Science and Computer Engineering, Las Vegas, Nevada, July, 2014. 